\title{
Hyperferritinemia as independent risk factor and biomarker in COVID-19 to predict severity and mortality.
}

\footnotetext{
1. MBBS, FCPS

Professor \& Head Hematology

Hayatabad Medical Complex,

Peshawar.

2. MBBS, FCPS

Associate Professor Hematology Hayatabad Medical Complex,

Peshawar.

3. MBBS, M.Phil, FCPS (PGR)

Professor Hematology

Nowshera Medical College, Nowshera

4. MBBS, FCPS

Professor of Hematology

Hayatabad Medical Complex,

Peshawar.

5. MBBS, FCPS (PGR)

Postgraduate Resident (PGR) FCPS

Hematology

Hayatabad Medical Complex,

Peshawar.
}

Correspondence Address:

Dr. Hamzullah Khan

Professor Hematology

Nowshera Medical College, Nowshera hamzakmc@gmail.com

Article received on:

26/10/2020

Accepted for publication:

$18 / 12 / 2020$

\begin{abstract}
Shahtaj Khan', Saiqa Zahoor², Hamzullah Khan ${ }^{3}$, Khalid Khan ${ }^{4}$, Mehreen Farooq ${ }^{5}$
\end{abstract}
ABSTRACT... Objectives: To determine the role of deranged serum ferritin levels as independent pathogenic risk factor to predict the progression towards a worse clinical outcome in COVID-19. Study Design: Descriptive cross sectional study. Setting: Hayatabad Medical Complex Peshawar. Period: 1 March to 10 July 2020. Material \& Methods: A total of 267 patients were enrolled from COVID-19 isolation units, Hayatabad Medical Complex Peshawar Descriptive statistics were used for numerical variables. Binary logistic regression analysis was used to predict the worst outcome in patients with deranged levels of ferritin. Correlation statistic were used to quantify the correlation of ferritin with mortality and severity of the disease. Kaplan Meir test was used for survival analysis to compare the mortality rate in gender groups in COVID-19 patients with deranged ferritin levels. Results: The mean age of the patients was $53+14$ years. The median value of the Serum ferritin levels of Covid-19 patients was $978 \mathrm{ug} / \mathrm{L}$ the ferritin distribution in gender groups was not normally distributed (Shapiro Wilk test, $p$-value $0.001) .215 / 267(80.5 \%)$ cases reported $>400 \mathrm{ug} /$ Lof serum ferritin. There was a statistically significant uphill positive correlation of serum ferritin levels with an increase in age $\left(r_{s} 0.213\right.$, $p-0.001)$ and with disease outcome in terms of mortality $\left(r_{s} 0.29, p-0.05\right)$. The probability case fatality in patients with deranged serum ferritin levels was 1.8 times more as compared to patients without hyperferritinemia ( $\mathrm{p}-0.05$, OR 1.8). The surviving capability in female gender with deranged ferritin levels in extreme of age was $65 \%$ as compared to $20 \%$ in male gender. Conclusion: More than $80 \%$ of the COVID-19 patients had abnormally higher readings of serum ferritin. The deranged ferritin levels had a statistically significant correlation with an increase in age of patient and with worst outcome in terms of death. Female gender more protective with higher chances of survival with deranged serum ferritin levels in all age groups compared to male gender.

Key words: $\quad$ COVID-19, Gender Perspective, Mortality, Pandemic, Serum Ferritin.

Article Citation: Khan S, Zahoor S, Khan H, Khan K, Farooq M. Hyperferritinemia as independent risk factor and biomarker in COVID-19 to predict severity and mortality. Professional Med J 2021; 28(8):1183-1189.

https://doi.org/10.29309/TPMJ/2021.28.08.6178

\section{INTRODUCTION}

COVID-19 is pandemic respiratory infectious disease with unknown etiology, was first reported to the WHO office on $31^{\text {st }}$ Dec 2019, from Wuhan, a metropolitan city in the province of Hubei China. ${ }^{1}$ The outbreak in 2019 was totally different with presentation of pneumonia of unknown cause, later on the Chinese Centre for Disease Control and Prevention and local CDC attributed it to a novel virus belonging to corona family and was termed as 2019-nCoV. ${ }^{2}$ Pakistan is not an exception and by $15^{\text {th }}$ September, the government sources declare 302,000 confirmed cases with 6389 deaths. 290,000 cases are recovered so for and 1316 cases are under treatment in high dependency units countrywide. ${ }^{3}$ We have been observing the COVID-19 pattern, risk factor and published on the impact of demographic variable. We noticed that the infection rate was 1.25 times more in males than females in our population. The case fatality rate was $5.41 \%$ in our population in early epidemics. The rate of infection was more common in younger age and mortality was more in older age irrespective of gender $(p=0.014){ }^{4}$

The cytokine storm (which is recognized as excessive and deranged production of inflammatory cytokines by the corona viruses) has been recognized as cause of death in COVID-19. ${ }^{5}$ Consequently the inflammatory markers like 
serum ferritin, d-dimers and C-reactive proteins, prolactin and erythrocytes sedimentation rate have been reported to predict the disease severity and mortality in COVID-19. ${ }^{6}$ Many studies reported from the city of Wuhan, China reported hyperferritnemia as predictor of mortality and severity of the disease..$^{7,8}$

The literature supported the fact that on admission to isolation wards the average ferritin concentration in COVID-19 patients was $>800$ $\mu \mathrm{g} / \mathrm{L}$. that was 5.3 times higher in patients with sever disease at time of presentation. ${ }^{9}$ Similarly in-hospital mortality was higher in patients with serum ferritin levels $>1400 \mu \mathrm{g} / \mathrm{L}$ as compared to the survivors with $<1400 \mu \mathrm{g} / \mathrm{L}$ ferritin which shows its impact on the mortality in COVID-19 patients. ${ }^{10}$

The abnormally deranged serum ferritin levels may be crucial for in COVID-19 patients. The serum ferritin levels are reported high in hospitalized patient with COVID-19. A study reported an increase in the ferritin levels exceeding the upper limit of detection, with increase in hospital stay. Similarly ferritin levels were higher in very critically ill patients (ICU patients) as compared to severe diseased patients. ${ }^{11}$

Present study was therefore designed with the objectives to determine the role of deranged serum ferritin levels as independent pathogenic risk factor to predict the progression towards a worse clinical outcome in COVID-19 in our population.

\section{MATERIAL \& METHODS}

This cross sectional study was conducted from $1^{\text {st }}$ March to $10^{\text {th }}$ July 2020 , in a tertiary care hospital of Peshawar. A total of 267 COVID-19 patients were included.

Assuming 4\% prevalence of COVID-19 in general population from the study of Zhou $X$ et al; ${ }^{12}$ a reference population of 100,000 patients was estimated to reside in the catchment area of our teaching hospital, Hayatabad Medical Complex Peshawar, Khyber Pakhtunkhwa, Pakistan. A sample size of 267 was calculated through Openepi software, an online sample size calculator, with Absolute precision of $5 \%$, confidence interval of $95 \%$, and a drop out of $10 \%$.

Only patients hospitalized with COVID-19 in isolation unit of HMC were included. Only covid-19 patients where serum ferritin was advised by the treating consultant were included irrespective of age and gender. Patients under study were observed for disease outcome in terms of satisfactory discharge or case fatality due to COVID-19.

COVID-19 patients where serum ferritin was not advised were excluded. Similarly all patients with any type of symptoms came to emergency or outdoor patients department or even confirmed patients of COVID-19 in isolation department where ferritin levels were not advised were also excluded.

About $2 \mathrm{ml}$ blood was drawn from each individual, by veni-puncture under aseptic condition. Blood in Gel bottles was stored for serum ferritin analysis. Then blood was centrifuged. Serum ferritin was measured on COBAS-511 (Roche Diagnostics), using commercial kits of Roche diagnostics as per the instructions of the manufacturer. A value of $<400 \mu \mathrm{g} / \mathrm{l}$ was taken as normal.

For COVID confirmation, PCR results of the nasopharyngeal swab duly reported in Public health research laboratory of the Hospital and also of the Khyber medical University (a designated Lab for PCR of 2019nCoV by the Government of Khyber Pukhtunkhwa) were considered only.

Ethical endorsement was obtained from the institutional ethical review board of Post-Graduate Medical Institute, Hayatabad Medical Complex under notification No (316/HEC/B \& PSC/2020 Dated $15^{\text {th }}$ May 2020).

Prior informed verbal consent was obtained from all suspects and they were assured of confidentiality.

\section{Operational Definition of Age}

As per Article 1 of The United Nations Convention on the Rights of the Child defines a child as "for 
the purposes of the present Convention, a child means every human being below the age of 18 years unless under the law applicable to the child, majority is attained earlieryoung adult 1935 years, middle-aged 36-55 years and older age $>56$ years. ${ }^{13,14}$

\section{Standard Values for Ferritin}

Keeping NHS-Government of $\mathrm{UK}^{15}$ standard values as 40-400 were considered as normal for both the genders in present study. Values above 400 were considered as abnormally higher and clinically significant. Similarly studies from the Wuhan China used 30-400 ug/L as the reference levels of ferritin as normal. ${ }^{16}$

The following reference ranges were based for interpretation of ferritin values. ${ }^{15,16}$

Low: Less than $15 \mathrm{ug} / \mathrm{L}$ Borderline: 16 - $40 \mathrm{ug} / \mathrm{L}$

Normal: $41-400 \mathrm{ug} / \mathrm{L}$

High: Greater than 400

Data was entered in SPSS, version 25 and descriptive and correlation statistics were applied. Numerical variables like age of patients and serum ferritin values were presented in median and range as the data was not normally distributed. The other numerical variable like age was presented with Mean and standard deviation. Correlation tests using Spearman ranked correlation was used to determine the correlation of serum ferritin with age categories and disease outcome. Binary logistic regression analysis was used to predict the probability of worst outcome interm of death with deranged ferritin levels. Kaplan Meir test was used for survival analysis to compare the mortality rate in COVID-19 patients under the influence of the elevated ferritin levels.

\section{RESULTS}

The mean with standard deviation of age of the patients was $53+14$ years. A minimum of 1 years with a maximum of 89 years of age was recorded with age range of 88 years. Mode of age was 60 years. The median value of the Serum ferritin levels of COVID-19 patients was $978 \mathrm{ug} / \mathrm{L}$. The minimum of the recorded values was 7.71 to a maximum of $5862 \mathrm{ug} / \mathrm{L}$ (Table-I). Out of total 267 patients $197(73.8 \%)$ were males and $70(26.2 \%)$ females. $122(45.7 \%)$ patients were in the age range $35-55$ years while $118(44.2 \%)$ of the patients had age more than 55 years. (Table-II). Shapiro-Wilk test of normality with Histogram with curve, when applied on the data of age and ferritin levels in both the genders, it was noted that the age data in both of the genders were normally distributed with insignificant $p$-value (o.12, 0.87 (Shapiro wilk test)) while the distribution of serum ferritin in COVID-19 patients was not distributed normally in group of gender $(p=0.001)$ (Figure-1).

We observed a statistically significant uphill positive correlation of serum ferritin levels in COVID-19 patients with an increase in age $\left(r_{s-}\right.$ 0.213 , p-0.001) (Table-IV, Figure-2). Similarly there was a moderate uphill positive, statistically significant, correlation of serum ferritin levels with worst outcome of the disease in terms of mortality $\left(r_{s-}\right.$ 0.29, p-0.05). (Table-III)

Using regression analysis to determine the probability of mortality in COVID-19 with deranged serum ferritin levels we observed that the probability of worst outcome in terms of mortality in COVID-19 with deranged serum ferritin levels was 1.8 time more as compared to patients with ferritin <400 ug/L. (p-0.05, OR 1.8). (Table-IV)

It was further observed using survival statistics with time to event analysis on Kaplan Meier test under the influence of the deranged serum ferritin levels in both genders, taking age in years as time variable and disease outcome in event, that the probability of surviving was $90-100 \%$ by age $<40$ years, $60 \%$ in age range $51-60$ years, $45 \%$ in age range $61-80$ years and astonishingly the survival plot touched the line of $20 \% \%$ when the age of the patients was 80 years or more in male gender. While in female gender probability of surviving was $80-90 \%$ by age $<60$ years and $65 \%$ for age $>80$ years. In male gender the survival drops vertically with age more than 80 years while no such graphical changes are seen for female patients. This representation confirms female gender more protective with higher chances of survival with deranged serum ferritin levels in all 
age groups compared to male gender (Figure-3).

\begin{tabular}{|l|c|c|c|}
\hline & Frequency & Percent & $\begin{array}{c}\text { Cumulative } \\
\text { Percent }\end{array}$ \\
\hline$<18$ years & 5 & 1.9 & 1.9 \\
\hline 19-35 years & 22 & 8.2 & 10.1 \\
\hline 36-55 years & 122 & 45.7 & 55.8 \\
\hline$>55$ years & 118 & 44.2 & 100.0 \\
\hline Total & 267 & 100.0 & \\
\hline
\end{tabular}

\begin{tabular}{|l|c|c|}
\hline & Age & Ferritin \\
\hline Number of patients & 267 & 267 \\
\hline Mean & 53 & 1186.43 \\
\hline Median & 55 & 977.80 \\
\hline Mode & 60 & 2000.00 \\
\hline Std. Deviation & 14 & 48.77 \\
\hline Range & 88 & 5855.29 \\
\hline Minimum & 1 & 7.71 \\
\hline Maximum & 89 & 5863.00 \\
\hline
\end{tabular}

Table-I. Descriptive statistics of age and serum ferritin.

\begin{tabular}{|l|c|c|c|}
\hline & Frequency & Percent & $\begin{array}{c}\text { Cumulative } \\
\text { Percent }\end{array}$ \\
\hline Male & 197 & 73.8 & 73.8 \\
\hline Females & 70 & 26.2 & 100.0 \\
\hline Total & 267 & 100.0 & \\
\hline
\end{tabular}

Table-II. Gender Distribution

Table-III. Age Categorization

\begin{tabular}{|l|c|c|c|}
\hline \multicolumn{1}{|c|}{} & \multicolumn{1}{|c|}{$\begin{array}{c}\text { Age Ordinal } \\
\text { Ranks }\end{array}$} & Ferritin \\
\hline \multirow{2}{*}{ Ferritin } & rs & $.213^{\star *}$ & \\
\hline \multirow{3}{*}{ Outcome } & $\mathrm{p}$ & 0.001 & \\
\hline & rs & -0.002 & 0.29 \\
\hline & $\mathrm{p}$ & 0.971 & 0.054 \\
\hline & Number & 267 & 267 \\
\hline
\end{tabular}

Correlation is significant at the 0.01 level (2-tailed).

Table-IV. Correlation matrix.

\section{Predicted}

Observed

Outcome

\begin{tabular}{|c|c|c|c|c|c|c|}
\hline \multirow{2}{*}{\multicolumn{3}{|c|}{ Observed }} & \multicolumn{2}{|c|}{ Uutcome } & \multirow{2}{*}{\multicolumn{2}{|c|}{ Percentage Correct }} \\
\hline & & & Discharged & & & \\
\hline \multirow{2}{*}{ Step 1} & \multirow{2}{*}{ Outcome } & Discharged satisfactorily & 225 & 0 & \multicolumn{2}{|c|}{100.0} \\
\hline & & Expired & 42 & 0 & & \\
\hline \multicolumn{7}{|c|}{ Variables in the Equation } \\
\hline & & B & S.E. & df & Sig. & $\operatorname{Exp}(B$ \\
\hline \multirow{4}{*}{ Step $1^{a}$} & Gender & -0.409 & 0.424 & 1 & 0.335 & 0.664 \\
\hline & Ferritin & 0.000 & 0.000 & 1 & 0.050 & 1.800 \\
\hline & Age & 0.054 & 0.245 & 1 & 0.825 & 1.056 \\
\hline & Constant & 1.756 & 1.015 & 1 & 0.084 & 0.173 \\
\hline
\end{tabular}

a. Variable(s) entered on step 1: gender, Ferritin, Age

Table-V. Binary logistic regression analysis of disease outcome with different variable (factors like age, gender and level of ferritin).

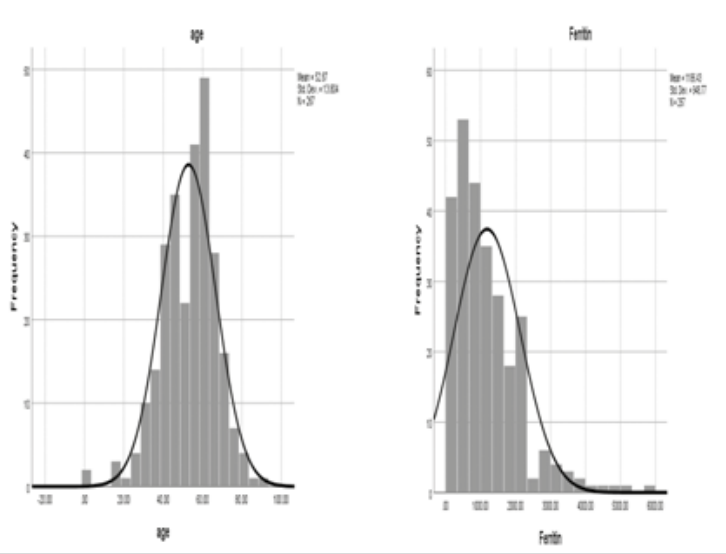

Figure-1. Distribution of data (age \& ferritin)

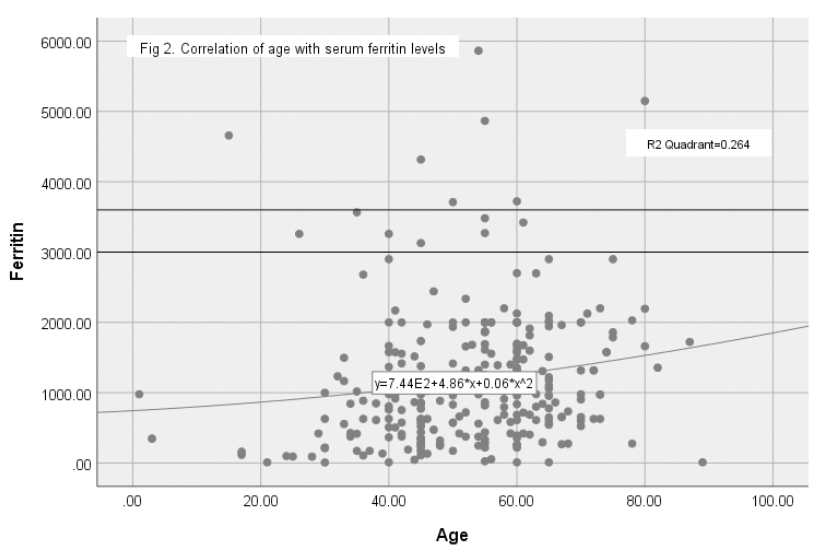

Figure-2. Correlation of age with serum ferritin levels 


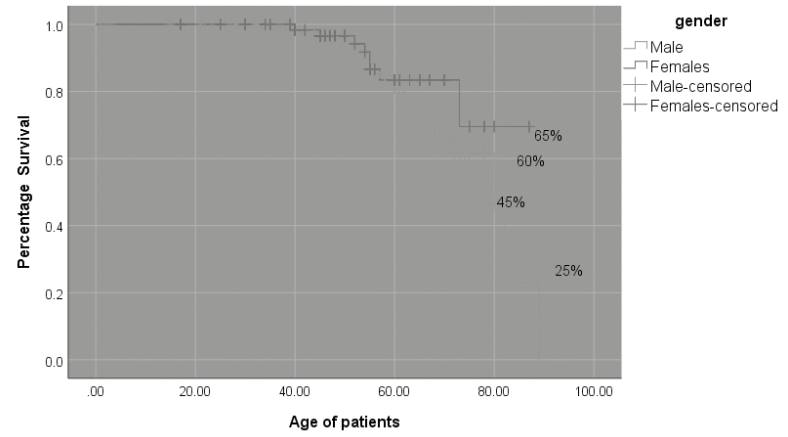

Figure-3. Correlation of age with serum ferritin levels

\section{DISCUSSION}

High ferritin levels are associated with inflammatory state in COVID-19 and is reported to be a useful marker to predict the severity of the disease and cytokine storm. The question is what is the source of the high levels of ferritin in the COIVD-19 inflammatory process so the possible explanation would be that the macrophages in the parenchyma of the lungs which produces the cytokines might be responsible for the increased secretion of ferritin in COVID-19. ${ }^{17}$ In present study we observed the median value of the Serum ferritin levels was 978 ug/L in Covid-19 patients. GómezPastora et $\mathrm{al}^{6}$ have reported the average levels of ferritin in severe cases of COVID-19 in their study that matches our findings. Schmidt S.M ${ }^{18}$ have reported that hyperferritinemia and altered iron homeostasis play a key role in pathogenesis of viral infections including COVID-19.

The distribution of serum ferritin in COVID-19 patients was not distributed normally in group of gender $(p=0.001)$. The same has been observed in the studies that ferritin levels in case of COVID-19 were lower in female patients as compared to male patient where a 2.4 time increase in ferritin above normal was recorded. Similarly other proinflammatory markers of inflammation including C-reactive proties (CRP) and IL-6 were above normal in both gender but comparatively lower in female gender which represent a lower cytokine storm in female COVID-19 patients. ${ }^{19}$

A statistically significant uphill positive correlation of serum ferritin levels in COVID-19 patients with an increase in age was observed in present study. A study reported that the in-hospital mortality was higher with an increase in age and in patients with serum ferritin levels $>1400 \mu \mathrm{g} / \mathrm{L}$ as compared to the survivors with $<1400 \mu \mathrm{g} / \mathrm{L}$ ferritin which shows the clinical impact of hyperferritinemia on mortality in COVID-19. ${ }^{10}$ Few other national level studies have also reported the cytokine storm with an elevation of inflammatory biomarkers like serum ferritin, d-dimers, CRP and prolactin. Similarly there was emphasis of increased levels of these mediators in male gender as compared to females genders and with an increase in age and hospital stay. ${ }^{20,21}$

Statistically significant correlation of serum ferritin levels with worst outcome of the disease in terms of mortality $\left(r_{s-} 0.29, p-0.05\right)$ was noted in our population infected with $2019 \mathrm{nCoV}$. Zhou et al ${ }^{10}$ also reported that the levels of the serum ferritin in deceased due to SAR-COV-2 infection were markedly higher as compared to the discharges patients throughout the clinical course observed in both the groups (Discharges vs Deceased). Thus the higher levels of the ferritin in COVID-19 predict morbidity and mortality. Similarly Zhi Lin ${ }^{22}$ reported that they distributed the study population in two groups with a cut off values of $500 \mathrm{ug} / \mathrm{L}$, they found that the group with hyperferritinemia had higher proportion of sever cases (31.82\% vs. $9.71 \%, P=0.0009$ ) and pulmonary infiltrates bilaterally $(95.45 \%$ vs. $79.61 \%, P=0.0297)$ as compared to patient without hyperferritnemia with COVID-19. Furthermore to reach the level of satisfaction in findings we applied regression analysis for knowing the probability of mortality with hyperferritnemia. We observed that the probability of worst outcome in terms of mortality in COVID-19 with deranged serum ferritin levels was 1.8 time more as compared to patients without hyperferritinemia. $(p=0.05$, OR 1.8). The same has been reported by the other researchers ${ }^{9,10,21,22}$ that is in concordance with our findings. Zhou et $\mathrm{al}^{10}$ reported a higher Odds ratio of 5.3 for mortality due to covid-19 in cases of hyperferritinemia.

Using time to event analysis with Kaplan Meir test, the probability of surviving was $90-100 \%$ by age $<40$ years, $60 \%$ in age range $51-60$ years, $45 \%$ in age range $61-80$ years and astonishingly 
the survival plot touched the line of $20 \%$ when the age of the patients was 80 years or more in male gender. While in female gender probability of surviving was $80-90 \%$ by age $<60$ years and $65 \%$ for age $>80$ years. This difference in competition for survival in gender groups in case of COVID-19 is inclining more in favor of female gender. One of the possible explanation reported claims that the IgG antibodies production in mild, moderate and severe COVID-19 in female gender tends to rise promptly as compared to males which may account for different outcome of COVID-19. ${ }^{23}$ Many factors could contribute for gender differences including low viral load in females because of less exposure as compared to the male gender in our religious society. Some of the scientists are of the opinion that the number of death reported are caused by the gender behavior (life style) i.e. smoking, drinking and working abroad are more among men as compared to women. ${ }^{24}$

Researchers have postulated the increased ferritin levels are associated with iron toxicity due to leakage of ferritin from damaged tissues in cases of severe inflammation and are responsible for worst outcome. ${ }^{25}$ Therefore knowing the limitation of the study we would suggest for future interventions to investigate the co-existing other iron parameters like transferring saturation, plasma iron and hepcidin levels to know about the iron toxicity due to leakage in cases of severe inflammation IN COVID-19.

\section{CONCLUSION}

We concluded that $80 \%$ of the COVID-19 patients had abnormally higher readings of serum ferritin $>400 \mathrm{ug} / \mathrm{L}$. The deranged ferritin levels had a statistically significant correlation with an increase in age of patient and with worst outcome in terms of death/mortality. Female gender more protective with more chances of survival with deranged serum ferritin levels in all age groups as compared to male gender.

Copyright@ 18 Dec, 2020.

\section{REFERENCES}

1. Guo YR, Cao QD, Hong ZS, Tan YY, Chen SD, Jin HJ, Tan KS, Wang DY, Yan Y. The origin, transmission and clinical therapies on corona virus disease 2019 (COVID-19) outbreak - an update on the status. Mil Med Res. 2020; 7(1):11. doi: 10.1186/s40779-02000240-0.

2. Chen N, Zhou M, Dong X, Qu J, Gong F, Han Y. et al. Epidemiological and clinical characteristics of 99 cases of 2019 novel coronavirus pneumonia in Wuhan, China: A descriptive study. Lancet. 2020; 395:507-13.

3. Coronavirus in Pakistan - Confirmed Cases". www. covid.gov.pk/. Retrieved 15th September 2020.

4. Khan, H., Hussain, S., zar, A., fawad, S. Analysis of demographic variables in acquiring infection and mortality due to COVID-19. Microbes and Infectious Diseases, 2020; 1(2): 70-76. doi: 10.21608/ mid.2020.34444.1030.

5. Qin C., Zhou L., Hu Z., Zhang S., Yang S., Tao Y., Xie C., Ma K., Shang K., Wang W., Tian D.S. Dysregulation of immune response in patients with coronavirus 2019 (COVID-19) in Wuhan, China. Clin. Infect. Dis. 2020 doi: $10.1093 /$ cid/ciaa248.

6. Gómez-Pastora J, Weigand $\mathrm{M}$, Kim $\mathrm{J}$, et al. Hyperferritinemia in critically ill COVID-19 patients - Is ferritin the product of inflammation or a pathogenic mediator? Clin Chim Acta. 2020; 509:249251. doi:10.1016/j.cca.2020.06.033.

7. Chen G., Wu D., Guo W., Cao Y., Huang D., Wang H., Wang T., Zhang X., Chen H., Yu H., Zhang X., Zhang M., Wu S., Song J., Chen T., Han M., Li S., Luo X., Zhao J., Ning Q. Clinical and immunological features of severe and moderate coronavirus disease 2019. J. Clin. Invest. 2020 doi: 10.1172/JCl137244.

8. 2. Qin C., Zhou L., Hu Z., Zhang S., Yang S., Tao Y., Xie C., Ma K., Shang K., Wang W., Tian D.S. Dysregulation of immune response in patients with coronavirus 2019 (COVID-19) in Wuhan, China. Clin. Infect. Dis. 2020 doi: 10.1093/cid/ciaa248.

9. Bai T., Tu S., Wei Y., Xiao L., Jin Y., Zhang L., Song J., Liu W., Zhu Q., Yang L., Chen H., Hou X. Clinical and laboratory factors predicting the prognosis of patients with COVID-19: an analysis of 127 patients in Wuhan, China. Lancet. 2020 doi: 10.2139/ ssrn.3546118. 
10. Zhou F., Yu T., Du R., Fan G., Liu Y., Liu Z., Xiang J., Wang Y., Song B., Gu X., Guan L., Wei Y., Li H., Wu X., Xu J., Tu S., Zhang Y., Chen H., Cao B. Clinical course and risk factors for mortality of adult inpatients with COVID-19 in Wuhan, China: A retrospective cohort study. Lancet. 2020; 395:1054-1062.

11. Vargas-Vargas $M$ and Cortés-Rojo $C$. Ferritin levels and COVID-19. Rev Panam Salud Publica. 2020; 44:e72. https://doi. org/10.26633/RPSP.2020.72.

12. Zhonghua Liu Xing Bing Xue ZaZhi. Novel coronavirus pneumonia emergency response epidemiology team. Prime PubMed, 2020; 41(2):145-51. DOI: 10.3760/cma.j.issn.0254-6450.2020.02.003.

13. (Unicef UK. The United Nations Convention on the Rights of the Child [internet]. Unicef London: [cited January 13, 2019]. Available at https://www.unicef.org. uk/what-we-do/un-convention-child-rights/.

14. Petry NM. A comparison of young, middle-aged, and older adult treatment-seeking pathological gamblers (internet). Gerontologist 2002; 42(1):92-9. https://www. southtees.nhs.uk/services/pathology/tests/ferritin/).

15. Ji D., Zhang D., Chen Z., Xu Z., Zhao P., Zhang M., Zhang L., Cheng G., Wang Y., Yang G., Liu H., Li B., Ji J., Lau G., Qin E. Clinical characteristics predicting progression of COVID-19. Lancet. 2020 doi: 10.2139/ ssrn.3539674.

16. Rosário C., Zandman-Goddard G., Meyron-Holtz E.G., D'Cruz D.P., Shoenfeld Y. The Hyperferritinemic Syndrome: Macrophage activation syndrome, Still's disease, septic shock and catastrophic antiphospholipid syndrome. BMC Med. 2013; 11:185.
17. Schmidt S.M. The role of iron in viral infections. Front Biosci. 2020; 25(4):4839.

18. Thomas, Liji. "Research explains recognized sex differences in COVID-19 outcomes". News-Medical. https://www.news-medical.net/news/20200803/ Research-explains-recognized-sex-differences-inCOVID-19-outcomes. aspx. (Accessed September 16, 2020).

19. Ashraf T, Lashari MN, Khowaja A. Management of Covid-19 in perspective of cardiologists. Pak Heart J 2020; 53(01):01-04.

20. Mahmud T, Ansarie M. COVID-19: Management. Jour Pak Med Assoc, 2020 (Suppl 3), 70(5): S64-68.

21. Lin Z, Long F, Yang $Y$, Chen X, Xu L, Yang M. Serum ferritin as an independent risk factor for severity in COVID-19 patients [published online ahead of print, 2020 Jun 24]. J Infect. 2020; S0163-4453(20)30434-5. doi:10.1016/j.jinf.2020.06.053.

22. Long, Q., Tang, X., Shi, Q. et al. Clinical and immunological assessment of asymptomatic SARSCoV-2 infections. Nat Med 26, 1200-1204 (2020). https://doi.org/10.1038/s41591-020-0965-6.

23. Bwire GM. Coronavirus: Why Men are More Vulnerable to Covid-19 than women? [Published online ahead of print, 2020 Jun 4]. SN Compr Clin Med. 2020; 1-3. doi:10.1007/s42399-020-00341-w.

24. Edeas M, Saleh J, Peyssonnaux C. Iron: Innocent bystander or vicious culprit in COVID-19 pathogenesis? Int J Infect Dis. 2020; 97:303-305. doi:10.1016/j.ijid.2020.05.110.

\begin{tabular}{|c|c|c|c|}
\hline \multicolumn{4}{|c|}{ AUTHORSHIP AND CONTRIBUTION DECLARATION } \\
\hline Sr. \# & Author(s) Full Name & Contribution to the paper & Author(s) Signature \\
\hline 1 & Shahtaj Khan & $\begin{array}{l}\text { Concept design, Data collection, } \\
\text { Manuscript writing. }\end{array}$ & \\
\hline 2 & Saiqa Zahoor & $\begin{array}{l}\text { Data collection, Manuscript writing, } \\
\text { Critical review. }\end{array}$ & \\
\hline 3 & Khalid Khan & $\begin{array}{l}\text { Data collection, Data analysis, } \\
\text { Critical review. }\end{array}$ & \\
\hline 4 & Hamzullah Khan & Data analysis, Manuscript writing, & \\
\hline 5 & & Data collection. & $s \sqrt{x+2}$ \\
\hline
\end{tabular}

